\title{
Relationship between Digital Literacy Awareness and Perceived Gossip Tendency among College Students
}

\author{
Dr. Chaiyaset Promsri* \\ Rajamangala University of Technology Phra Nakhon, Bangkok, Thailand \\ ${ }^{*}$ Corresponding Author \\ Dr. Chaiyaset Promsri \\ Email- chaiyaset.p@rmutp.ac.th
}

\author{
Article History \\ Received: 25.08.2019 \\ Accepted: 03.09.2019 \\ Published: 10.09 .2019
}

\begin{abstract}
The purpose of this study was to examine the relationship between digital literacy awareness and perceived gossip tendency. Samples were selected from 60 college students in management program at a selected public university in Bangkok by using a self-administrated questionnaire for gathering data. Digital Literacy Awareness and Tendency to Gossip Questionnaire were employed for data collection, which validity and reliability tests were conducted to ensure the quality of scale measurement. To explore the association between digital literacy awareness and perceived gossip tendency, Pearson correlation was analyzed. Results indicated no significant relationship between digital literacy awareness and perceived gossip tendency $(r=.231, p>.05)$. Nonetheless, findings of this study found significant correlations between digital literacy awareness and achievement dimension $(r=$ $.284, p<.05)$ and social information dimension $(r=.258, p<.05)$ at a low level. This study was noteworthy to be the first study in this area that sought to explore the relationship between digital literacy awareness and tendency to gossip. Findings of this present study were beneficial for further studies to utilize as a fundamental knowledge to enhance understanding in this topic. Limitations and recommendations for further studies were also discussed.
\end{abstract}

Keywords: Digital literacy, digital literacy awareness, Gossip Tendency, College students.

\section{INTRODUCTION}

Learning of today's students becomes more complex and advanced than their teachers can imagine, especially the way that they utilize digital technology to be part of their learning components [1]. To effectively learn new topics and subjects on distinctive online platforms, students are required to have sufficient digital literacy. Digital literacy is viewed as one element of digital citizenship, which an individual needs to be responsible for what they utilize technology to interact with the digital world. Digital literacy is often understood as an ability to search for, assess, and create clear information through communication on distinctive digital platforms [2]. However, to possess this skill set, students need to realize and be aware of the importance of digital literacy, which refers to the term digital literacy awareness. Digital literacy awareness refers to an individual's ability to understand an importance of digital literacy and know how to use digital device and equipment in one's daily life. Prior research has studied the importance of digital literacy awareness among college students, which included the level of digital resource usage and digital technology usage proficiency [3].

Gossip is a social phenomenon that can be frequently seen in all society in daily life. Gossip is viewed as a negative behavior in which an individual talks about a non-existing person's story. Guendouzi [4] noted that gossip is a kind of communications when a person who is mentioned does not physically appear at that moment. Although gossip is perceived as an undesirable behavior in the society, it is inevitable in people's life and sometimes provides benefits to an individual in particular the relationship enhancement. Previous research confirms this notion as it reports that people who gossip want to satisfy their psychological and social needs such as reducing their uncertainty and maximizing social networking via shared sensitive information [5]. Various reasons can help describe why people tend to gossip. Manaf, Ghani, and Jais [6] noted that individuals gossip because they need to receive some information or use that information to control others or to make fun. In a digital age, gossip can be devastatingly spread at lightning speed to countless people through various digital platforms. In the light of this, gossiping has lifted up to a new level when it has been spread in social media leading to cyberbullying [7]. Digital Marketing Community [8] reports that 42 percent of teenagers

Copyright @ 2019: This is an open-access article distributed under the terms of the Creative Commons Attribution license which permits unrestricted use, distribution, and reproduction in any medium for non commercial use (NonCommercial, or CC-BY-NC) provided the original author and source are credited. 
were afraid of being gossiped online leading to make them stressed. Hence, students need to be aware of using technology and realize the importance of digital literacy in relation to gossip tendency.

Despite the concepts of digital literacy and gossip tendency have been increasingly investigated in the past decades, an examination on the linkage between these two terms has been ignored from the literature even though they might have some overlapped elements in common. In order to fill the literature gap, this study attempted to seek for the association between digital literacy awareness and perceived gossip tendency. This study was remarkable to be the first study in these topics that paid attention on exploring the relationship between these two variables. Findings of this study were to help strengthen and provide benefits, and could be used as a fundamental understanding to enhance knowledge in these topics in the future. Therefore, the purpose of this study was to examine relationship between digital literacy awareness and gossip tendency.

\section{LITERATURE REVIEWS \\ Digital Literacy Awareness}

The continued increase of utilizing technology in daily life enhances the requirement of sufficient knowledge and skills in using technology in all levels of education and employment status to accomplish tasks more effectively and efficiently. The expansion of using online media content as a primary platform for collecting and sharing information challenges individuals to have better understanding of how to organize and create information for their benefits [9]. This skill set refers to "digital literacy." The concept of digital literacy has been progressively studied and discussed since this term was firstly introduced by Gilster [10]. Although numerous scholars have provided the definitions of digital literacy in which some mutual elements have been shared, no overall consensus on related skills and knowledge that best describe inclusive scope of this concept. Digital literacy terms and concepts have been developed based on the prior conceptions such as computer literacy, information literacy, and network literacy [11].

The American Library Association (ALA) [12] defines digital literacy as "the ability to use information and communication technologies to find, evaluate, create, and communicate information, requiring both cognitive and technical skills." Often, digital literacy refers to an ability to seek for, assess, and compose explicit information through communication on distinctive digital platforms. Digital literacy somehow refers to the combination of knowledge, skill, and behaviors individual possesses while utilizing digital devices to engage in online communities and social networks. Digital literacy is often defined and understood as an ability to produce, receive, send, and share the information through digital codification on the digital device [13]. According to JISC [14], digital literacies are defined as "those capabilities which fit an individual for living, learning and working in a digital society." In addition, this institution proposes seven elements of digital literacies, which include media literacy, communication and collaboration, career and identity management, ICT literacy, learning skills, digital scholarship, and information literacy.

Digital literacy is perceived to be an important skill for people in today's society and needed to be consistently evaluated to ensure their promptness of utilizing this literacy in their daily life. The readiness of using digital devices in various platforms alludes to what is so called "digital literacy awareness." Digital literacy awareness was defined as an individual's ability to understand an importance of digital literacy and know how to use digital device and equipment in one's daily life.

\section{Tendency to Gossip}

Gossip is broadly defined as the spread of information about new and negative behaviors of other people who do not exist at that moment [15]. Gossip is different from rumor in which gossip focuses on individuals while rumor places an emphasis on events rather than people. To determine gossip, three basic conditions need to be taken into consideration including (1) the listener needs to be interested in the information, (2) it is quite difficult to terminate instantly but also reliable, and (3) taking hold of attention [16]. Since gossip is viewed as a deviant behavior, it is quite difficult to measure how people gossip or tendency to gossip of individuals. In the light of this, Nevo, Nevo, and Derech-Zehavi [17] developed the scale measurement called "Tendency to Gossip Questionnaire", which encompassed four essential dimensions of gossip: physical appearance, achievement, social information, and sublimated gossip. Although this instrument received a highly reliability score and loading factors when checked the convergent validity, some items in each dimension are still skeptical as it does not completely represent that specific dimension. Nonetheless, past research has employed this scale measurement for data collection, in particular Thai context [5]. To briefly describe each dimension, physical appearance refers to the tendency to talk with friends about other people's clothes and individual appearance. Achievement refers to the tendency to talk with friends about other people's achievement, salaries, and success at work. Social information refers to the tendency to talk with friends about other's people problem at work, compatibility of couples, other people's dating and love affairs, and Sublimated gossip refers to the tendency to read gossip column in tabloid, and biographies of well-known people [17].

\section{Methodology}

This empirical study aimed at examining the association between digital literacy awareness and gossip tendency. A total of 60 students who studied in management program at a selected government university was selected for data collection by using a selfadministrated questionnaire. A newly developed tool called "Digital Literacy Awareness", which contained a 14-item of 5-point rating scale ranging from $1=$ strongly disagree to $5=$ strongly agree was utilized to measure digital literacy while perceived gossip tendency was evaluated by the use of Tendency to Gossip Questionnaire (TGQ) developed by Nevo et al., [17]. This instrument consisted of 19- 
item of 6-point rating scale ranging from $1=$ never to $6=$ always. To guarantee the quality of these scale measurements, reliability with Cronbach's alpha test was conducted. Table-1 demonstrated that alpha scores of these scales were highly acceptable, according to Nunnally [18]. To answer a research objective, Pearson correlation was conducted to explore the relationship between digital literacy awareness and gossip tendency.

Table-1: Reliability of Scale Measurements

\begin{tabular}{|c|c|c|}
\hline Scales & Number of Items & Alpha's Score \\
\hline Digital Literacy Awareness & 14 & 0.83 \\
\hline Tendency to Gossip & 19 & 0.94 \\
\hline
\end{tabular}

\section{RESULTS}

Findings of this study showed that the preponderance of participants were female $(51.7 \%)$ with the average age between 18-25 years old (71.7\%). In addition, results found that the total mean score of perceived digital literacy awareness among these respondents was at a high level $(M=3.48$, S.D. $=.491)$. For tendency to gossip, the total mean score of perceived gossip tendency was at a moderate level $(M=3.61)$ which could be described that these participants occasionally gossiped about other people. To consider each dimension of gossip tendency score, 'physical appearance' was rated as the highest mean score $(M=3.40$, S.D. $=$ 1.092) followed by 'achievement' $(M=3.22$, S.D. = .984), 'social information' ( $M=3.02$, S.D. $=1.077)$, and 'sublimated gossip' (M= 2.97, S.D. $=1.030$ ), respectively.

To scrutinize the relationship between digital literacy awareness and perceived gossip tendency, Pearson correlation was computed by using a statistical computer program. Results showed no significant correlation between overall digital literacy awareness and perceived gossip tendency $(r=.231, p>.05)$. However, when explored the association between digital literacy awareness and each dimension of perceived gossip tendency, findings revealed that digital literacy awareness was positively correlated to achievement dimension $(r=.284, p<.05)$ and social information dimension $(r=.258, p<.05)$ at a low level (see Table 2$)$.

Table-2: Correlation between Digital Literacy Awareness and Gossip Tendency $(n=60)$

\begin{tabular}{|c|c|c|c|c|c|}
\hline & PA & Ach & \multicolumn{1}{c|}{ SI } & Sub & \multicolumn{1}{c|}{ TGQ } \\
\hline DLA & .048 & $.284^{*}$ & $.258^{*}$ & .227 & .231 \\
& $(.714)$ & $(.028)$ & $(.047)$ & $(.081)$ & $(.075)$ \\
\hline
\end{tabular}

*Significant Level at .05, ${ }^{* *}$ Significant Level at $.01 \mathrm{DLA}=$ Digital Literacy Awareness, PA = Physical Appearance, Ach = Achievement SI = Social Information, Sub = Sublimated Gossip, and TGQ = Tendency to Gossip

\section{Conclusion, Discussions, And ReCOMmendations}

This study was noteworthy to be the first study in its field to scrutinize the association between digital literacy awareness and gossip tendency. Although this study found no significant relationship between digital literacy awareness and gossip tendency, results demonstrated the positive correlation between digital literacy and some dimensions of perceived gossip tendency including achievement and social information. As respondents in this study were students, their focus on using digital technology and equipment might be varied. However, if digital literacy awareness was understood as an individual's ability to understand an importance of digital literacy and know how to use digital device and equipment in their daily life, information they tended to share with their friends about other people was lifestyles, secrets, and stories. Thus, it was not surprised to find the relationship between digital literacy awareness and achievement and social information dimensions. However, these relationships were found at a low level, which needed to be extended in a further study to investigate the robustness of correlation when sample sizes were increased.

Like other studies, this study has some limitations. Firstly, the sample size of this study was too small, which affected the generalization of this study. Thus, the next study should increase the sample size to be more quantifiable. Secondly, the digital literacy awareness scale developed in this study did not encompass all aspects of digital literacy. Hence, the further study should expand versions of digital literacy awareness scale measurement to ensure that digital literacy awareness would be fully evaluated. Lastly, this study examined only correlation between digital literacy awareness and perceived gossip tendency, not causation. Therefore, the research application and implementation needed to be taken into consideration when interpreting the findings. For benefits of this research, it can be used as a fundamental study to enhance knowledge in this area in future.

\section{ACKNOWLEDGEMENT}

I am very thankful to Rajamangala University of Technology Phra Nakhon for publication sponsorship and facility supports.

\section{REFERENCES}

1. Poore, M. (2011). Digital Literacy: Human Flourishing and Collective Intelligence in a Knowledge Society. Australian Journal of Language and Literacy, 19(2):20-26. 
2. Hsieh, Y. (2012). Online social networking skills: The social affordances approach to digital inequality. First Monday, 17(4). http://www. firstmonday.org/htbin/cgiwrap/bin/ojs/index.php/fm/article/view/3893/3192

3. Tabusum, S., Saleem, A., \& Batcha, S. (2014). Digital literacy awareness among arts and science college students in Tiruvallur district: A study. International Journal of Managerial Studies and Research, 2(4), 61-67.

4. Guendouzi, J. (2001). You'll think we're always bitching': the functions of cooperativity and competition in women's gossip. London, UK: SAGE Publications.

5. Promsri, C. (2015). Gender differences in gossip tendency of Thai's university students: a case of RMUTP students. Proceeding of Interdisciplinary Research at Phetchaburi Rajabhat University, Phetchaburi, Thailand.

6. Manaf, M., Ghani, E., \& Jais, I. (2013). Gossip has it! An in-depth investigation of Malaysian employees on gossip activities at workplace. Canadian Social Science, 9(4): 34-44.

7. Scheff, S. (2017). Digital shaming: 10 ways online gossip turns into cyberbullying. Retrieved from https://www.huffpost.com/entry/digital-shaming-10-ways-online-gossip-turns-into- cyberbullying

8. Digital Marketing Community. (2018). Digital marketing statistics \& metrics: What makes teenagers feel stressed online, 2018. Retrieved from https://www.digitalmarketingcommunity.com/indicators/teenagers-feel-stressed-online-2018/

9. Osterman, M. D. (2012). Digital literacy: Definition, theoretical framework, and competencies. In Plakhotnik, M. S., Nielsen, S. M., \& Pane, D. M. (Eds.), Proceedings of the 11th Annual College of Education \& GSN Research Conference (pp. 135-141). Miami: Florida International University. Retrieved from http://education.fiu.edu/research_conference/

10. Belshaw, D. A. J. (2012). What is digital literacy? A Pragmatic investigation. Retrieved from https://clalliance.org/wpcontent/uploads/files/doug-belshaw-edd-thesis-final.pdf

11. Boechler, P., Dragon, K., Washiewski, E. (2015). Digital literacy concepts and definitions: Implications for education assessment and practice. Retrieved from https://pdfs.semanticscholar.org/5781/dd5c39284ba7495b6fc3a4fa1ac32beae870.pdf

12. American Library Association (ALA) Digital Literacy Task Force (2013). ALA Task Force releases digital literacy recommendations. Retrieved from http://www.ala.org/news/press-releases/2013/06/ala-task-force-releases-digital-literacyrecommendations

13. Heick, T. (2019). The definition of digital literacy. Retrieved from https://www.teachthought.com/literacy/the-definition-of-digitalliteracy/

14. JISC. (2014). Developing digital literacies. Provides ideas and resources to inspire the strategic development of digital literacies -those capabilities which support living, learning and working in a digital society. Retrieved from https://www.jisc.ac.uk/guides/developing-digital-literacies

15. Okazaki, S., Rubio, N., \& Campo, S. (2014). Gossiping behavior on social networking sites: Does gender matter? International Journal of Human-Computer Interaction, 30, 718-726

16. Guerin, B., \& Miyazaki, Y. (2006). Analyzing rumors, gossip, and urban legends through their conversational properties. Psychological Record, 56, 23-33.

17. Nevo, O., Nevo, B., \& Derech-Zehavi, A. (1993). The development of the tendency to gossip questionnaire: construct and concurrent validation for a sample of Israeli college students. Educational and Psychological Measurement, 53, 973-981.

18. Nunnally, J. C. (1978). Psychometric theory. New York, NY: McGraw-Hill. 